\title{
A Study of Psychological Well Being Among Male and Female College Students
}

\author{
Dr. Ramesh D. Waghmare ${ }^{1 *}$
}

\section{ABSTRACT}

The purpose of the present study was to investigate the impact of gender and location of the college students on psychological well being. The sample for the study comprised of 100 college students from jalna city. In each 50 male students (25 urban and 25 rural male students) and 50 female students (25 Urban and 25 rural female college students). The scale was used for data collection psychological well being scale by Bholge and prakash (1995). Where gender and location were considered as independent variables and psychological well being as dependent variables. 2x2 factorial design was used and data were analysis by Mean, SD and 't' values. Results revered no significant difference between male and female, Urban and Rural college students on psychological well being.

Keywords: Psychological Well Being, Gender, Location

Well being is a concept that encompasses a well rounded, balanced and comprehensive experience of life. It includes health in social, physical, mental, emotional, career and spiritual domains. Well being a positive outcome that is meaningful for people and for many sectors of society, because it tells us that people perceive that their lives are going well. Better living conditions are fundamental to well being. Psychology well being is a concept in psychology that related with the health our health is well we can behave good and other hand our life become so easy. About psychological well being is important with respect to how we function and adapt and with respect to whether our lives are satisfying and productive. Psychological well being is a state of mind desirable for one and all. Some of the characteristics associated with psychological well being are optimism, positive work attitudes, understanding, reaching out to people, maintaining good health, ability to sustain relationships, able to handle crisis effectively etc. psychological well being can describe as a state of mind with an absence of a metal disorder from the perspective of positive psychology it may include an individual's ability to enjoy life and create a balance between life activities and efforts to achieve psychological resilience.

\footnotetext{
${ }^{1}$ Godawari College Ambad, Dist. Jalna. (M.S.), India

*Responding Author

(C) 2016 I R Waghmare; licensee IJIP. This is an Open Access Research distributed under the terms of the Creative Commons Attribution License (http://creativecommons.org/licenses/by/2.0), which permits unrestricted use, distribution, and reproduction in any Medium, provided the original work is properly cited.
} 


\section{A Study of Psychological Well Being Among Male and Female College Students}

Psychological wellbeing means the positive psychological functioning of the individual. Students with psychological wellbeing possess good mental health and maintain good relationship with other individuals. They are productive in nature and maintain positive attitude towards their life.

Psychological well-being means individual's construction of concepts to develop him in order to be able to feel happy. In this context, individual should be able to delay his pain, he should be able to do that and struggle even though psychological well-being hurts.

\section{REVIEW OF LITERATURE}

Rathi (2007) examined that male and female students of adolescence period did not different significantly in their well being. Gill (2007) found that there was no significant difference between male and female college students on psychological well being. Jasraj kaur (2015) indicated that there was no significant difference between psychological well being of male and female high schools students, Akter (2015) reported females to be higher on psychological well being than male. Kotar(2013) found that there is no significant mean difference between the psychological well being among the male and female college students. Tony Jose and Akhila Thomas (2005) indicated that there is no significant difference between psychological wellbeing and resilience among Psychology students and Engineering students. The result also shows that there is no significant difference between wellbeing with respect to the gender of the participants whereas. Bryant found gender pattern in spirituality among college samples while Ryff and Keyes (1995) and Roothman and colleagues (2003) found no difference between the males and females in this aspect.

\section{Statement of the problem}

- $\quad$ To study the psychological well being among college students.

\section{OBJECTIVES}

- To examine the psychological well being among male and female college students.

- To examine the psychological well being among urban and rural college students.

\section{Hypotheses}

- There is no significant difference between male and female college students dimension on psychological well being.

- There is no significant difference between urban and rural college students dimension on psychological well being.

\section{METHODS}

\section{Participants}

The present study sample 100 was selected from college students of Jalna district in Maharashtra. The effective sample consisted of 100 subjects out of which 50 male students ( 25 urban and 25 rural students) and 50 female students ( 25 urban and 25 rural students). Stratified random sampling method was employed to select the unit of sample. The subject selected in this 


\section{A Study of Psychological Well Being Among Male and Female College Students}

sample will be used in the age group of 18 years to 21 years (Mean-18.63 and SD- 1.90) and Ratio 1:1. Thus total sample includes as shown in the following table.

\section{Gender}

\section{Location}

\begin{tabular}{|l|l|l|l|}
\hline & Male & Female & Total \\
\hline Urban & 25 & 25 & 50 \\
\hline Rural & 25 & 25 & 50 \\
\hline Total & 50 & 50 & 100 \\
\hline
\end{tabular}

\section{Research design}

Research design to be implemented in the present research is as follow:

$2 x 2$ factorial designs use for the present study.

\section{A}

B

\begin{tabular}{|l|l|l|}
\hline & A1 & A2 \\
\hline B1 & A1, B1 & A2, B1 \\
\hline B2 & A1, B2 & A2, B2 \\
\hline
\end{tabular}

A- Gender A1- Male A2- female

B- Location B1- Urban B2- Rural

Variables of the Study

\begin{tabular}{|l|l|l|l|}
\hline Variable & Type of variable & $\begin{array}{l}\text { Sub. } \\
\text { variable }\end{array}$ & Name of variable \\
\hline Gender & Independent & 2 & $\begin{array}{l}\text { 1) Male } \\
\text { 2) Female }\end{array}$ \\
\hline Location & Independent & 2 & $\begin{array}{l}\text { 1) Urban } \\
\text { 2) Rural }\end{array}$ \\
\hline Psychological well being & Dependent & - & - \\
\hline
\end{tabular}

Instruments

\begin{tabular}{|l|l|l|}
\hline Aspect & Name of the Test & Author \\
\hline $\begin{array}{l}\text { Psychological } \\
\text { well being }\end{array}$ & $\begin{array}{l}\text { Psychological well-being } \\
\text { scale.(1995) }\end{array}$ & Bholge and prakash \\
\hline
\end{tabular}

\section{PSYCHOLOGICAL WELL -BEING SCALE:}

Psychological well-being Questionnaire by Bhogle and Prakash (1995), was used to measure Psychological well-being. The questionnaire contains 28 items with true and false response 10 alternative. It covers 13 dimensions of psychological well-being. The maximum possible score is twenty eight and minimum is zero. High score indicates high level of psychological well-being. The test -retest reliability coefficient is 0.72 and internal consistency coefficient is 0.84 . 


\section{A Study of Psychological Well Being Among Male and Female College Students}

\section{Procedure}

The following research methodology was used in the present study.

The primary information was gathered by giving personal information from to each to each student. The students were called in a small group of 10 to 15 students. To fill the inventories subjects were given general instructions belongs to each scale. The students provided the psychological well being scale.

\section{Data analysis}

The data were analyzed as follows.

The Mean and SD with graphical representation for Gender (Male and Female College Students) on psychological well being was analyzed. A simple design was selected to adequate of statistical analysis of ANOVA in order to examine the roll of main as well as subsequently on students psychological well being.

\section{RESULTS AND DISCUSSION}

Table No.01 Show the mean, SD and F value of psychological well being and Gender.

\begin{tabular}{|l|l|l|l|l|l|l|l|}
\hline Gender & Mean & SD & N & DF & $\begin{array}{l}\text { Mean } \\
\text { Difference }\end{array}$ & F & Sign \\
\hline Male Students & 19.10 & 2.31 & 50 & \multirow{2}{*}{5} & 0.75 & 0.97 & NS \\
\hline Female Students & 19.85 & 1.96 & 50 & & & \\
\hline
\end{tabular}

Observation of the table No.01 indicated that the mean value of two classified group seems to differ from each other on psychological well being. The mean and SD value obtained by the male college students 19.10, SD 2.31 and Female College students was 19.85, SD 1.96, but on the basis of mean observation it would that mean difference 0.75 Both group ' $F$ ' ratio was 0.97 at a glance those female college student shows miner high score than Male college students.

In the present study was first hypothesis related psychological well being and Gender. It was "There is no significant differences between Male and Female college students on demotion psychological well being. Gender effect represent the psychological well being was no significant (F- 0.97, 1and 99, P- NS). This is no significant 0.05 and 0.01 levels because they obtained ' $F$ ' value are low than table values at 0.05 and 0.01 . In the present study was found that male and female college students no differ from psychological well being. The findings of the supported the first hypothesis, they are first hypothesis Accepted the present study. Finding was found that there is no significance difference between male and female on psychological well being.

A Opposite finding was found that Akter (2015) reported females to be higher on psychological well being than male. A similar finding was found that Rathi (2007), Gill (2007), Jasraj kaur 
(2015) and Kotar(2013) found that there is no significant mean difference between the psychological well being among the male and female college students.

Table No.02 Show the mean, SD and F value of psychological well being and Location.

\begin{tabular}{|l|l|l|l|l|l|l|l|}
\hline \multicolumn{1}{|c|}{ Location } & Mean & SD & N & DF & $\begin{array}{l}\text { Mean } \\
\text { Difference }\end{array}$ & F & Sign \\
\hline Urban Students & 18.91 & 1.75 & 50 & & & \\
\hline Rural Students & 19.10 & 2.12 & 50 & 98 & 0.19 & 0.57 & NS \\
\hline
\end{tabular}

Observation of the table No.02 indicated that the mean value of two classified group seems to differ from each other on psychological well being. The mean and SD value obtained by the urban college students 18.91, SD 1.75 and rural College students was 19.10, SD 2.12, but on the basis of mean observation it would that mean difference 0.19 . Both group ' $F$ ' ratio was 0.57 at a glance those rural college student shows miner high score than urban college students.

In the present study was second hypothesis related psychological well being and Location. It was "There is no significant difference between Urban and Rural college students on demotion psychological well being. Location effect represent the psychological well being was no significant (F- 0.57, 1and 99, P- NS). This is no significant 0.01 and 0.05 levels because they obtained ' $F$ ' value are low than table values at 0.01 and 0.05 . In the present study was found that urban and rural college students not differ from psychological well being. The findings of the supported the second hypothesis, they are second hypothesis Accepted the present study. Finding was found that there is significance difference between Urban and Rural college students on psychological well being.

\section{LIMITATIONS OF THE STUDY}

1) The finding of the study is based on very sample.

2) The sample was restricted to Jalna city in Maharashrta.

3) The study was restricted to only B.A. arts college students (arts facility) only.

4) The study was restricted students are only 18-21 years only.

\section{CONCLUSION}

- There is no significance difference between psychological well being than male and female college students.

- There is no significance difference between urban and rural college students on psychological well being.

\section{REFERENCES}

Akhter, S. (2015). Psychological well being in students of Gender difference. The International Journal of Indian psychology. 2 (4). 


\section{A Study of Psychological Well Being Among Male and Female College Students}

Astin, A. \& Astin, H. (2004). Spirituality in higher education: a national study of college students' search for meaning and purpose. Retrieved November 9, 2011 from.

Bhogle, S. and Jay Prakash, I., (1995), Development of the psychological well-being questionnaire, Journal of Personality and Clinical studies,Vol.11 (1\&2), PP.5-9.

Bryant, A.N. (2007). Gender differences in spiritual development during the college years. Springer Science. Doi:10/1007/s11199-007-9240-2. Retrieved from.

Diener, E. and Smith, H. (1999). Subjective well being : Three decades of progress. Psychological bulletin, 125, 276-302.

Fan, D. \& Ellison, C. (2008). Daily spiritual experiences and psychological well-being among US adults. Social Indicators Research,88 (2),247-271.

Fujita, F., Diener, E., \& Sandvik, E. (1991). Gender differences in negative affect and wellbeing: The case for emotional intensity. Journal of Personality and Social Psychology, 61, 427-434.

Fujita, F., Diener, E., \& Sandvik, E. (1991). Gender differences in negative affect and wellbeing: The case for emotional intensity. Journal of Personality and Social Psychology, $61,427-434$.

Gill, N. (2007). A study of psychological well being among college students of Haryana in Relation to coping Behaviour. M. Phil. Dissertation in Education, Chowdhary Devi Lal University, Sirsa.

Honmore, V.,M., and Jadhav, M.G., ( 2015) Psychological well being, Gender and Optimistic Attitude among college students. The International Journal of Indian psychology. 3, 1, 174-184.

Kaur Jasraj, ( 2015). well being improves mental health of school students. International Journal in Multidisciplinary and Academic Research ( SSIJMAR), 2,3, 1-5.

Kotar, A. B., ( 2013) A comparative study of psychological well being among Art's and science college students. Acme International Journal of multidisciplinary Research, I, 9-12.

R Waghmare (2016), A Study of Birth Order and Adjustment among College Students, International Journal of Indian Psychology, Volume 3, Issue 2, No.4, DIP: 18.01.074/20160302, ISBN: 978-1-329-85570-0

Rathi, Neerpal (2007) Meaning in life and psychological well being in pre adolescents and Adolescents. Journal of the Indian Academy of Applied Psychology. 33 (3), 31-38.

Roothman, B., Kirsten, D., Wissing, M. (2003). Gender differences in aspects of psychological well-being. South African Journal of Psychology, 33(4), 212-218.

Ryff, C. \& Keyes, C. (1995). The structure of psychological well-being revisited. Journal of Personality and Social Psychology,69 (4), 719-727.

Tony Jose and Akhila Thomas (2005) "Resilience and Psychological Wellbeing Among Psychology Students and Engineering Students- A Comparative Study", International Journal Scientific Research (IJSR), 4, (6), 498-499.

How to cite this article: R Waghmare (2016), A Study of Psychological Well Being Among Male and Female College Students, International Journal of Indian Psychology, Volume 3, Issue 3, No. 7, DIP: 18.01.118/20160303, ISBN: 978-1-365-12175-3 